\title{
Upgrading bio-based acetone to diacetone alcohol by aldol reaction using Amberlyst A26-OH as catalyst
}

\author{
M. Eisenacher ${ }^{1,5}$ (D) M. Venschott ${ }^{2,5} \cdot$ D. Dylong ${ }^{1} \cdot$ W. F. Hoelderich ${ }^{3,5} \cdot$ J. Schütz $^{4}$. \\ W. Bonrath ${ }^{4}$
}

Received: 17 December 2021 / Accepted: 13 January 2022 / Published online: 30 January 2022

(c) The Author(s) 2022

\begin{abstract}
The aldol reaction of bio acetone in presence of a strongly basic ion exchange resin was carried out with and without the addition of water in a temperature range between $-30{ }^{\circ} \mathrm{C}$ and $45^{\circ} \mathrm{C}$. The conversion, selectivity and service time of the ion exchange resins were investigated in a stirred batch reactor and a continuous fixed bed reactor. For the batch experiments, both conversion and selectivity increased with decreasing temperature. Furthermore, the addition of water to the reaction medium has a positive effect on selectivity and catalyst service time of the resins. For the continuous flow experiments carried out in a fixed bed reactor, the selectivity towards diacetone alcohol is higher than in a batch reactor. This high selectivity is favored by a short contact time which inhibits as expected most of the consecutive reactions.
\end{abstract}

Keywords Aldol reaction · Basic ion exchange resin · Diacetone alcohol - Water addition

M. Eisenacher

matthias.eisenacher@th-koeln.de

1 Circular Transformation Lab Cologne, TH Köln (University of Applied Sciences), Campus

Leverkusen, Kaiser-Wilhelm-Allee, 51368 Leverkusen, Germany

2 IU International University of Applied Sciences, Juri-Gagarin-Ring 152, 99084 Erfurt, Germany

3 TCHK Hoelderich Consultancy, 67227 Frankenthal, Germany

4 DSM Nutritional Products Ltd., Wurmisweg 576, CH-4303 Kaiseraugst, Switzerland

5 Present Address: Department of Chemical Technology and Heterogeneous Catalysis, RWTH Aachen University, Worringerweg 1, 52074 Aachen, Germany 


\section{Introduction}

In order to shift our current society and industry to more environmentally friendly alternatives, scientists from different disciplines have been looking for possibilities to replace petrochemical processes by sustainable biorefinery approaches to produce chemicals such as $n$-butanol. $N$-Butanol which is derived from the acetone-butanol-ethanol (ABE) fermentation is of increasing interest as a biofuel. [1-3]

In addition to that, $n$-butanol is a platform chemical with market sales of around 3.75 to 4.65 billion USD per year [4] and is mainly used in the production of cleaning products, plasticizer, lubricants, coating and painting additives [5].

However, ABE fermentation is not just producing $n$-Butanol: the process is also yielding ethanol, hydrogen, carbon dioxide and acetone [6]. Especially the formation of acetone is undelightful under economic reasons, since acetone is formed in large amounts as byproduct in the phenol process resulting in a cheap price [7].

Therefore, the chemical industry has been looking for applications and products which are derived from acetone. Such a product is diacetone alcohol. Diacetone alcohol is formed via aldol reaction of two equivalents acetone [8-10].

The aldol reaction of acetone (Fig. 1) leads to 4-hydroxy-4-methyl-2-pentanone, commonly referred as diacetone alcohol (DAA) followed by a dehydration to form mesityl oxide (MO).

Diacetone alcohol is used as a solvent [11], as an intermediate in the manufacturing of mesityl oxide [12] and as a reactant for the manufacturing of fragrances [13].

Processes to manufacture diacetone alcohol start with the aldol reaction of two equivalents acetone in presence of a basic catalyst [14].

These processes are on the one hand challenged by the need to suppress the dehydration of diacetone alcohol and on the other hand by the fact, that the reactions thermodynamic equilibrium is shifted to higher yields of the desired product at low temperatures, since aldolisation reactions are exothermic reactions [15, 16]. However, processes catalyzed by homogeneous catalysts also face the problem, that separation of the reaction mixture and the catalyst is expensive and that the contact time cannot be adjusted exactly.

In order to overcome these challenges, companies have been looking for alternatives during the last decades.

Mitsubishi Chemicals disclosed a process for the manufacturing of diacetone alcohol catalyzed by a solid basic catalyst comprising at least a metal hydroxide selected among the hydroxides of alkali metals and the hydroxides of alkaline earth
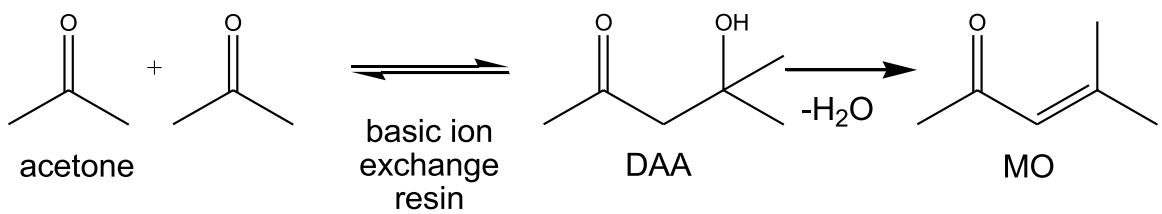

Fig. 1 Aldol reaction of acetone to DAA and condensation to MO 
metals and a binder [17]. Sabic disclosed a process in presence of a neutral heterogeneous catalyst which contains crystalline metal alumosilicates [18].

DSM showed that basic ion-exchange resins can also catalyze aldol reactions as a cost efficient alternative to aforementioned heterogeneous catalysts [19].

Other approaches to reach a high yield process for the manufacturing of diacetone alcohol are the catalytic distillation (CD) or the use of hydrotalcites as catalysts [20-24].

Acidic ion-exchange resins can be used for aldol reaction and aldol condensation, too $[25,26]$. In comparison to basic catalysis, acidic catalysis produces much more side products, e.g. MO and mesitylene. Therefore, the aldol reaction in the presence of strong basic ion-exchange resins can be of advantage. However, additional data on reaction kinetics and catalyst deactivation are needed in this context.

Basic ion-exchange resins are sensitive to high temperatures. The maximum operation temperature for the type 1 ion exchange resin Amberlyst $\mathrm{A} 26 \mathrm{OH}$, which was used for our kinetic studies is at about $60{ }^{\circ} \mathrm{C}$ [27]. At temperatures above the maximum operation temperature the service time of the ion exchange resins is shortened significantly due to the Hofmann elimination of active sites [28]. Therefore, lower temperatures have two beneficial effects: Thermodynamic equilibrium is shifted to the product DAA, and the lifetime of the ion exchange resins is increased.

Thotla et al. showed that water can be used as a selectivity enhancer in an acid catalyzed reactive distillation of acetone [24]. In the case of basic ion exchange resins the use of water can boost the selectivity as mentioned in two patents [29, 30]. In addition, an increased service time of the catalyst can be expected.

Kinetic studies for the aldol condensation of acetone in a batch reactor over a basic ion exchange resin at $54{ }^{\circ} \mathrm{C}$ were carried out by Podrebarac and Rempel $[31,32]$. For batch and catalytic distillation experiments they used the $\mathrm{OH}$-form of Amberlite IRA 900. This is a macroreticular type 1 ion-exchange resin marketed by DuPont. The studies showed, that for higher reflux flow rates, the selectivity for DAA increases substantially, but is limited by external mass transfer. High reflux flow rates also increase the production rate of MO. The initial production rate declines due to catalyst deactivation and eventually reaches a steady state. Further kinetic and thermodynamic investigations on the equilibrium between DAA and $\mathrm{MO}$ in the presence of phosphoric acid at temperatures between $25{ }^{\circ} \mathrm{C}$ and $70{ }^{\circ} \mathrm{C}$ were published by Kim and Hatfield [33]. The reaction rates for both hydration and dehydration increased with the acid concentration and were first-order with respect to reactant concentration (including water). For high acid concentrations and with increasing temperature, the equilibrium was shifted towards MO.

In order to better understand the ion-exchange resin catalyzed manufacturing of diacetone alcohol, Amberlyst A26OH [34], a strongly basic macroreticular type 1 ion exchange resin marketed by DuPont, was investigated as catalyst for this reaction. Furthermore, the influence of the reaction parameters on the conversion, selectivity and catalyst lifetime were studied.

Therefore, experiments in a stirred batch reactor and a continuous fixed bed reactor have been carried out. In addition to that, low temperatures (range: $30{ }^{\circ} \mathrm{C} /+45^{\circ} \mathrm{C}$ ) are applied, and the addition of water to the reaction medium is used to increase selectivity and service time of the catalyst. 


\section{Results and discussion}

\section{Mechanistic investigations}

First, the reaction products were identified and the reaction mechanism was investigated. As described in literature [8-10] the reaction of acetone yields DAA, the dehydration from DAA to MO and the consecutive reactions e.g. to isophorone and mesitylene. However, according to our investigations, the GC analysis of the reaction mixture gave hints towards aldol condensation leading to a different reaction scheme (Fig. 2). The primary product of the aldol reaction is DAA. As described in literature, DAA can eliminate water forming MO. Two other products directly based on DAA have been identified.

One is the iso-mesityl oxide (i-MO), which is formed in contradiction to Zaitsev's rule, when one of the two $\mathrm{CH}_{3}$ groups is deprotonated instead of the $\mathrm{CH}_{2}$ group. I-MO is a side product which is always formed in addition to MO. Thereby the conjugated double bond is thermodynamically favored. The normal content of i-MO of the product mixture after the dehydration of DAA with an acidic catalyst is about $5 \%$ [35]. In contrast, in our presented reactions much higher concentrations of i-MO have been found i.e. up to $40 \%$ of the dehydration products, possibly due to the different reaction mechanism under basic conditions.<smiles>CC(=O)[CH-]C(C)=O</smiles>

acetone

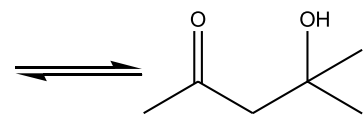

DAA<smiles>CC(=O)C=C(C)C</smiles>

MO
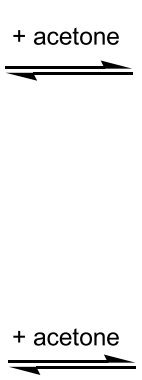

i-MO

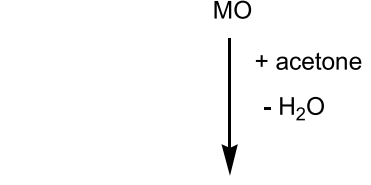

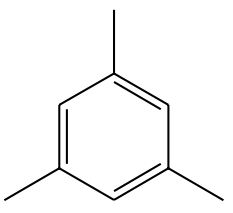

mesitylen

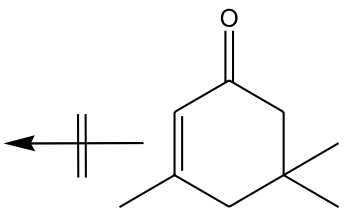

isophorone<smiles>CC(C)(O)CC(=O)CC(C)(C)O</smiles>

TAA<smiles>CC(C)=CC(=O)CC(C)(C)O</smiles>

semiphorone<smiles>CCCCCCCO</smiles><smiles>CC(C)=CC(=O)C=C(C)C</smiles>

phorone

Fig. 2 Reaction scheme of the aldol condensation of acetone 
As second DAA-based product the triacetone alcohol (TAA) was detected. TAA is formed when a DAA molecule reacts with an additional acetone in an aldol reaction. At low temperatures TAA was observed to be the main by-product because the elimination reaction did not take place.

Two possible reaction paths of MO with acetone were identified as illustrated in Fig. 2: in the first case a methyl group can react with the carbonyl carbon of acetone. The resulting product is semiphorone which can also result from the elimination of water out of TAA.

The second possibility is the 1,4-Michael addition. Under the given conditions the product of the 1,4-Michael addition will immediately undergo an intramolecular aldol condensation yielding isophorone (Fig. 2). The sequence of Michael addition and intramolecular aldol condensation is also named Robinson annulation [36].

In an experiment using $50 \mathrm{~mL} \mathrm{MO}$ as starting material over $3 \mathrm{~g}$ Amberlyst A26OH (containing $0.7 \mathrm{~g}$ water) at $20^{\circ} \mathrm{C}$ for $24 \mathrm{~h}$ no measurable conversion to DAA was observed. The same experiment using DAA as starting material showed the described equilibrium of acetone, DAA, MO and TAA after $4 \mathrm{~h}$. Therefore, under these conditions it is demonstrated that aldol addition steps are in an equilibrium.

The formation of phorone, which may result from the dehydration of semiphorone, is known from literature [37]. Also the formation of mesitylene from isophorone is mentioned in literature [38]. Both reactions are supposed to be catalyzed by acids. Both products have not been detected in our reaction mixtures which may be explained by the strongly basic reaction conditions which have been chosen.

The concentration of isophorone in the reaction mixtures was always higher than the concentration of phorone. This indicates that for the reaction of mesityl oxide with acetone the Michael addition is favored over the aldol addition.

\section{Batch experiments}

To determine the theoretically possible conversion of Acetone to DAA over Amberlyst A26OH batch experiments were carried out. Fig. 3 shows the conversion and the DAA selectivity over the time.

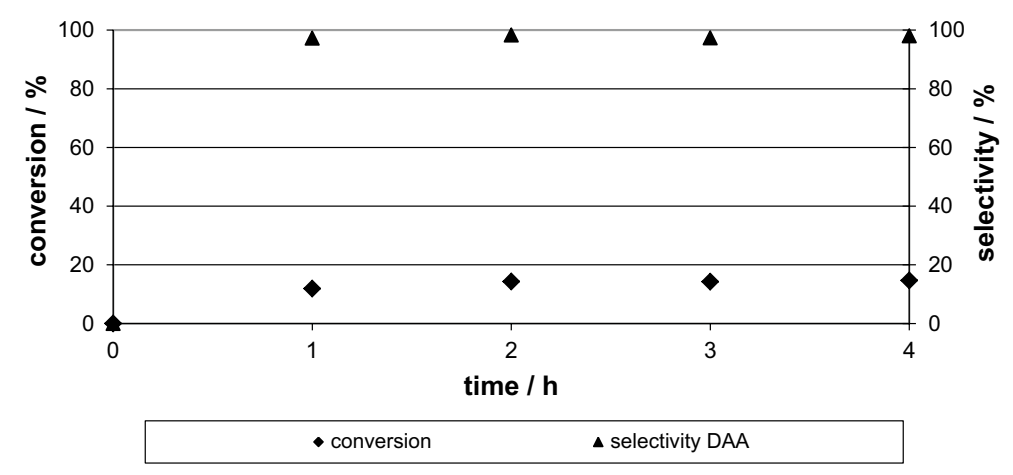

Fig. 3 Conversion and DAA selectivity over time; batch reaction with $3 \mathrm{~g} \mathrm{~A} 26 \mathrm{OH} ; 20{ }^{\circ} \mathrm{C} ; 5 \%$ water addition 
The results show the expected feasibility of the reaction. The gradient of the conversion is high within the first $60 \mathrm{~min}$, which leads to a conversion of $11.9 \%$ after $1 \mathrm{~h}$. After that, the conversion is only slightly increasing, from $14.3 \%$ after $2 \mathrm{~h}$ to $14.7 \%$ after $4 \mathrm{~h}$. Analyzed samples, which were taken after $75 \mathrm{~h}$ and $92 \mathrm{~h}$ still show an increasing conversion of $15.0 \%$ and $15.4 \%$.

The selectivity is high after the first hour (97\%) and then keeps constant in the range of $97-98 \%$ after $2-4 \mathrm{~h}$. After $75 \mathrm{~h}$ and $92 \mathrm{~h}$ the selectivity decreases to $87.6 \%$ and $85.7 \%$. The reaction of acetone to DAA seems to be faster than its consecutive conversion to form the three by-products TAA, i-MO, and MO. Furthermore, the trend of the selectivity and of the conversion indicate that the thermodynamic equilibrium is still not reached. Fig. 4 shows the influence of the temperature ( 9 experiments, temperature range from 0 to $+45^{\circ} \mathrm{C}$ in $5{ }^{\circ} \mathrm{C}$ steps) on the conversion of acetone over the time in the presence of Amberlyst A26OH.

The nine experiments confirm the results of the first run (Fig. 3) and show independent from the temperature the same trend. In the first hour, the conversion is strongly increasing (e.g. $10.0 \%, 30{ }^{\circ} \mathrm{C}, 1 \mathrm{~h}$ ). Later, the gradient (e.g. $0.044 \%$ $\mathrm{h}^{-1}, 30^{\circ} \mathrm{C}$ ) such as the conversion increase (e.g. $14.2 \%, 30^{\circ} \mathrm{C}, 96 \mathrm{~h}$ ) is quite low.

Nevertheless, the equilibrium conversion scalar is strongly dependent on the temperature and increases with decreasing temperature. After $1 \mathrm{~h}$ the conversion of the run at $0{ }^{\circ} \mathrm{C}(14.7 \%)$ is more than double than the conversion of the run at $45{ }^{\circ} \mathrm{C}(6.4 \%)$. The average conversion gap between these two temperatures $\left(0{ }^{\circ} \mathrm{C}\right.$ and $45^{\circ} \mathrm{C}$ ) is $11.2 \%$ and quite constant over the experimental runtime. For example, after $96 \mathrm{~h}$ the gap is $10.0 \%\left(21.8 \%, 0{ }^{\circ} \mathrm{C}\right.$ and $\left.11.8 \%, 45^{\circ} \mathrm{C}\right)$.

Due to the anti-correlation of conversion and temperature, it can be assumed, that the endothermic reaction rate seems to be higher than the exothermic reaction rate. In addition, the chemical equilibrium is not reached after $96 \mathrm{~h}$, the conversion over time gradient is not zero. The results indicate that with increasing reaction temperatures the chemical equilibrium shifts to the educt side. At lower

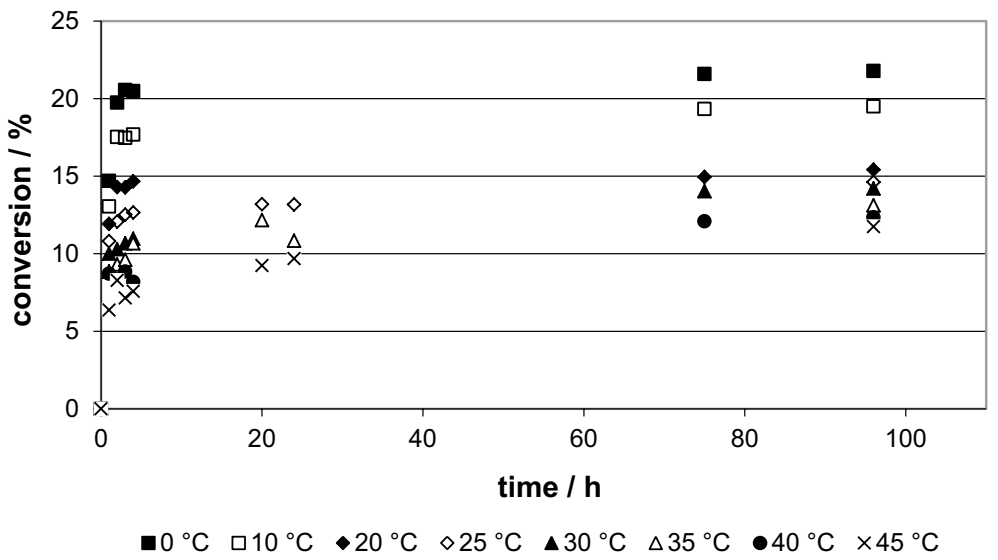

Fig. 4 Conversion over time; batch reaction with $3 \mathrm{~g} \mathrm{~A} 26 \mathrm{OH} ; 0{ }^{\circ} \mathrm{C} /+45^{\circ} \mathrm{C} ; 5 \%$ water addition 
reaction temperatures the equilibrium shifts towards the product (and side-product) side, but conversion does not exceed $25 \%$.

In addition to the conversion, selectivity in dependence upon reaction temperature and time were investigated (Fig. 5).

The results show that after $1 \mathrm{~h}$ the DAA selectivity is relatively independent from the reaction temperature and very high (maximum $98.9 \%, 10{ }^{\circ} \mathrm{C}$, minimum $96.9 \%$, $45{ }^{\circ} \mathrm{C}$ ). With increasing runtime, the shown selectivity functions depend on the temperature.

At $0{ }^{\circ} \mathrm{C}$ the selectivity slightly and continuously decreases from $98.7 \%$ after $1 \mathrm{~h}$ of runtime to $92.3 \%$ after $96 \mathrm{~h}$. With increasing temperatures, the gradient of selectivity decrease per time increases as well. At $45^{\circ} \mathrm{C}$ the highest selectivity drop occurs (96.9\% after $1 \mathrm{~h}, 48.5 \%$ after $96 \mathrm{~h}$ ).

The GC analysis shows that with increasing runtime and increasing temperature side products reactions to $\mathrm{MO}$ and TAA occur. At $0{ }^{\circ} \mathrm{C}$ TAA is the only by-product. Moreover, at higher temperatures the equilibrium of the side products is shifted from TAA to MO.

The statistical analysis of the presented results shows the expected significant correlation between conversion and the two factors temperature and time.

$$
\begin{gathered}
U=18.47512+0.03569 \times t-0.24672 \times T \\
0 h \leq t \leq 96 h \\
0^{\circ} C \leq T \leq 45^{\circ} C \\
R^{2}=0.9579
\end{gathered}
$$

The multiple regression analysis show, that the conversion is stronger dependent on temperature than on time.

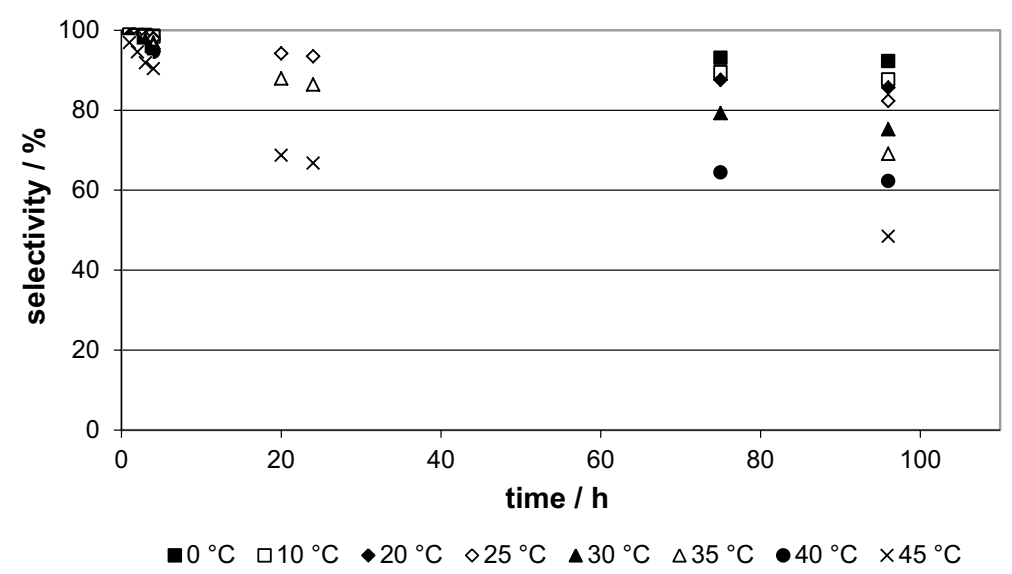

Fig. 5 DAA Selectivity over time; batch reaction with $3 \mathrm{~g} \mathrm{~A} 26 \mathrm{OH} ; 0{ }^{\circ} \mathrm{C} /+45^{\circ} \mathrm{C} ; 5 \%$ water addition 
In addition, the selectivity function dependent on the two factors temperature and time is calculated as follow.

$$
\begin{gathered}
S=106,70339-0.23053 \times t-0.37629 \times T \\
0 h \leq t \leq 96 h \\
0^{\circ} C \leq T \leq 45^{\circ} C \\
0 \% \leq S \leq 100 \% \\
R^{2}=0.7059
\end{gathered}
$$

The multiple regression analysis show, that the selectivity is more or less equal dependent on temperature and time and the determination is lower compared to the determination of the conversion.

In summary, the batch experiments show the principal feasibility of the DAA formation out of acetone. Low temperatures (e.g. $0{ }^{\circ} \mathrm{C}$ ) leads to medium conversions $\left(>20 \%\right.$ at $\left.0{ }^{\circ} \mathrm{C}\right)$ and high selectivities $\left(>90 \%\right.$ at $\left.0{ }^{\circ} \mathrm{C}\right)$. Moreover, short runtimes favor high selectivities and reduces side product formations.

\section{Continuous flow experiments using a fixed bed reactor}

In addition to the batch experiments, continuous flow experiments were carried out.

In Fig. 6 conversion and selectivity changes are illustrated over time on stream (TOS) in a continuous plug flow reactor resulting to be constant.

The results show in addition to batch experiments the principal feasibility of the DAA formation out of acetone in a continuous fixed bed reactor.

The selectivity is constant over the time (range: $97.6 \%$ after $2 \mathrm{~h}-98.3 \%$ after $96 \mathrm{~h}$ ) and only reduced by minor amounts of MO and TAA. The conversion is in good accordance with the results obtained under theoretical consideration in the

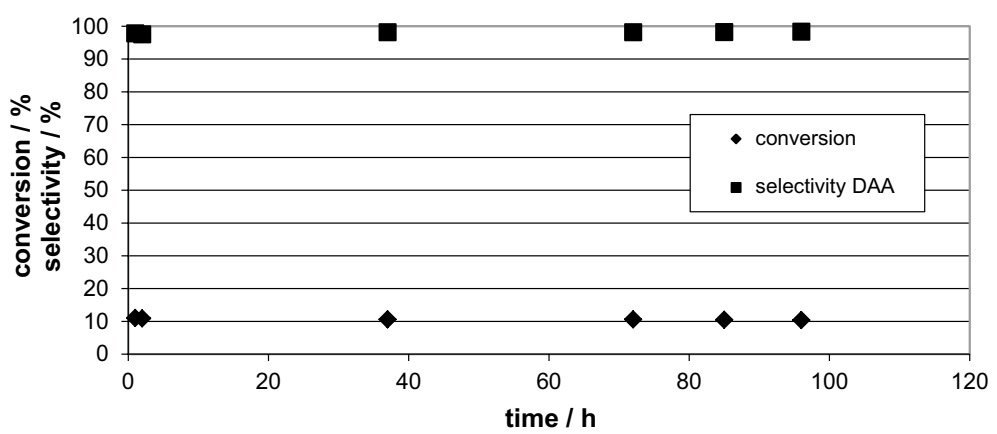

Fig. 6 Conversion and selectivity over time. $6 \mathrm{~g} \mathrm{~A} 26 \mathrm{OH}$ at $30{ }^{\circ} \mathrm{C}$ in a fixed bed reactor with a flow of $1 \mathrm{~mL} \mathrm{~min}^{-1}$ and $5 \%$ water addition 


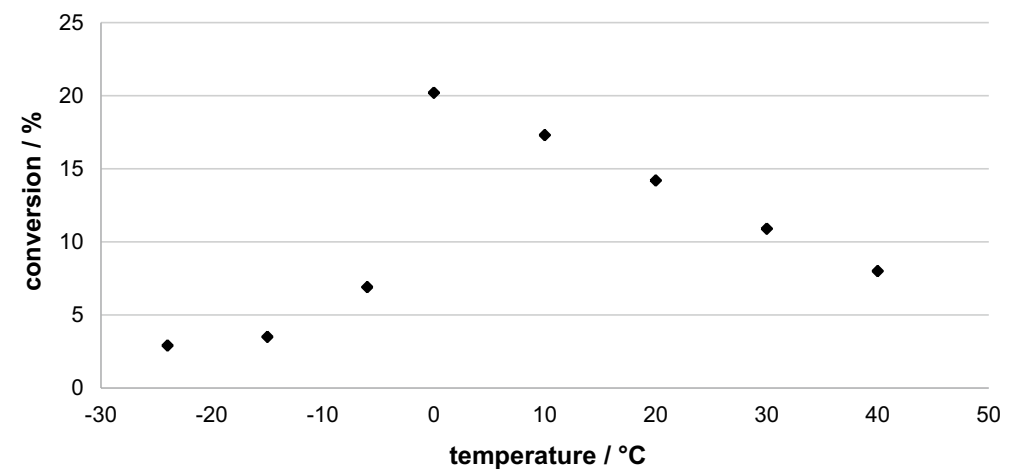

Fig. 7 Conversion over temperature. $6 \mathrm{~g}$ A26OH at $-24^{\circ} \mathrm{C} / 40^{\circ} \mathrm{C}$ in a fixed bed reactor with a flow of $1 \mathrm{~mL} \min ^{-1}$ and $5 \%$ water addition

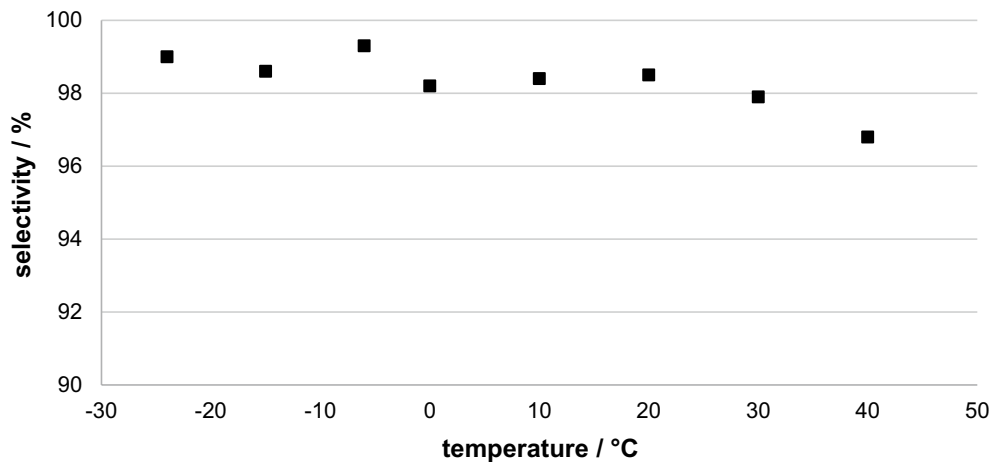

Fig. 8 Selectivity over temperature. $6 \mathrm{~g} \mathrm{~A} 26 \mathrm{OH}$ at $-24{ }^{\circ} \mathrm{C} /+40{ }^{\circ} \mathrm{C}$ in a fixed bed reactor with a flow of $1 \mathrm{~mL} \min ^{-1}$ and $5 \%$ water addition

batch reactions. The range of the conversion is between $10.4 \%$ after $96 \mathrm{~h}$ and $11.1 \%$ after $1 \mathrm{~h}$.

To determine the effect of the temperature, several runs were conducted in the range of $-24{ }^{\circ} \mathrm{C} /+40{ }^{\circ} \mathrm{C}$. The results are shown in Figs. 7 and 8 .

Between $0{ }^{\circ} \mathrm{C}$ and $40{ }^{\circ} \mathrm{C}$, the conversion is linear decreasing with increasing temperature $\left(-0.31 \% /{ }^{\circ} \mathrm{C}\right)$. This is expected according to the results obtained in the batch reactions. Below $0{ }^{\circ} \mathrm{C}$ the reaction rate decreases very fast. The sudden decrease could be caused by catalyst shrinkage which leads to bad diffusion of the starting material and the products in the catalyst pores.

The selectivity reaches highest values in the range of $-24{ }^{\circ} \mathrm{C}$ and $-6{ }^{\circ} \mathrm{C}$. In the range between $0{ }^{\circ} \mathrm{C}$ and $40{ }^{\circ} \mathrm{C}$ the selectivity drops slightly due to the formation of MO and TAA. In accordance with the batch experiments, the equilibrium of the side products shifts with higher temperatures from TAA to MO. The GC analysis quantify the temperature dependence of the by-products as follows. At 
low temperature a minor amount of TAA was measurable (TAA selectivity of $1.8 \%$ ). With increasing temperature, the TAA formation decreased continuously to $0.4 \%$ at $40{ }^{\circ} \mathrm{C}$. On the other hand, the MO formation increases constantly with higher temperatures $\left(0 \% \mathrm{MO}\right.$ selectivity at $0{ }^{\circ} \mathrm{C}, 2.8 \%$ MO selectivity at $40{ }^{\circ} \mathrm{C}$.

In Fig. 9, the influence of the flow rate is observed.

The graphical analysis of the data shows different tendencies. As expected, lower flow rates lead to higher contact times and thereby to higher conversions. This effect occurs at positive temperatures. Below $0{ }^{\circ} \mathrm{C}$ the conversion is mostly independent from temperature and contact time. As expected before, this could be caused by catalyst shrinkage.

The DAA selectivity is mostly independent from the contact time. At the same contact times, no obvious correlation between temperature and DAA selectivity was observed. The expected temperature dependent trend of decreasing selectivity with increasing temperature is confirmed by the experiments with catalyst contact time of $3.8 \mathrm{~min}$ and the 1.9 .

The maximum of the conversion $(20.2 \%)$ was observed at $0{ }^{\circ} \mathrm{C}$ and a contact time of $7.6 \mathrm{~min}$. This corresponds to the value of the equilibrium conversion at $0{ }^{\circ} \mathrm{C}$. For these conditions the weight hourly space velocity WHSV is $7.9 \mathrm{~h}^{-1}$.

The general influence of water on the reaction in the fixed bed reactor was studied. Medium conditions were chosen (Fig. 10).

The addition of water results in the literature known effect of higher conversions. In average the conversion is $4.9 \%$ higher. Furthermore, the addition of water shows steady state results of conversion (between $11.3 \%$ and $13.2 \%$ ) and selectivity (between $96.9 \%$ and $99.0 \%$ ). Without water the conversion continuously decreases from 8.2 to $5.0 \%$. Counterwise to the conversion, the selectivity increases from 86.0 to $97.0 \%$ Fig. 11 .

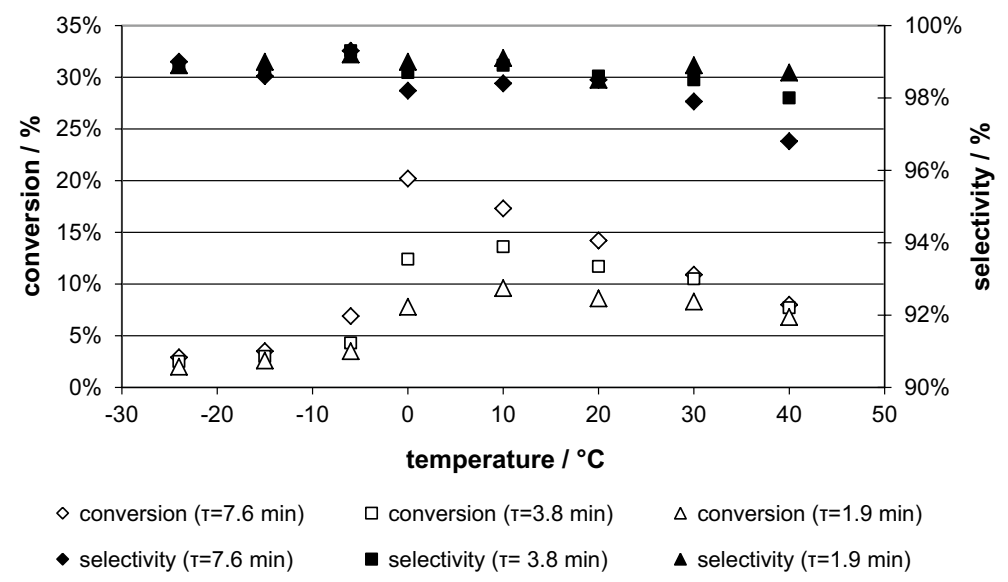

Fig. 9 Conversion and selectivity over temperature. $6 \mathrm{~g} \mathrm{~A} 26 \mathrm{OH}$ at $-24{ }^{\circ} \mathrm{C} / 40{ }^{\circ} \mathrm{C}$ in a fixed bed reactor with a catalyst contact time $(\tau)$ of $7.9,3.8$ and 1.9 min and $5 \%$ water addition 


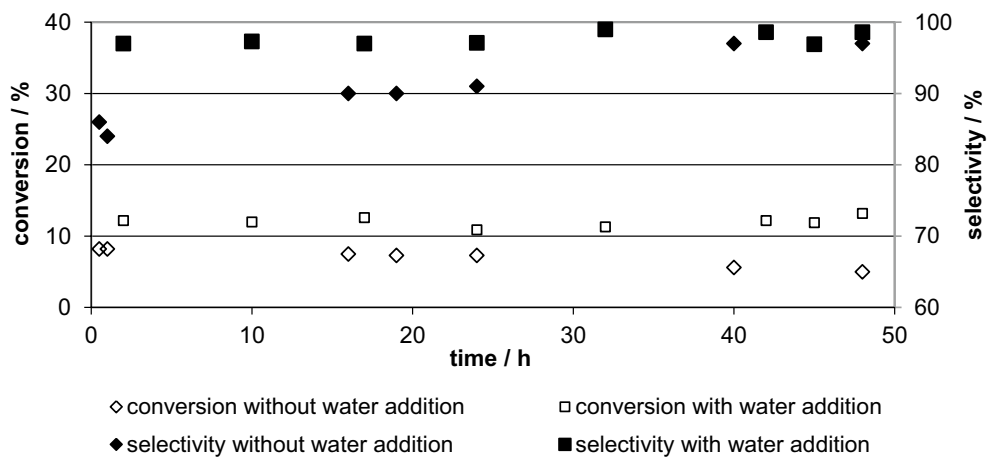

Fig. 10 Conversion and selectivity over time. 6 g A26OH with $0 \%$ and $5 \%$ water addition at $20{ }^{\circ} \mathrm{C}$ and a flow rate of $2 \mathrm{~mL} \mathrm{~min}^{-1}$

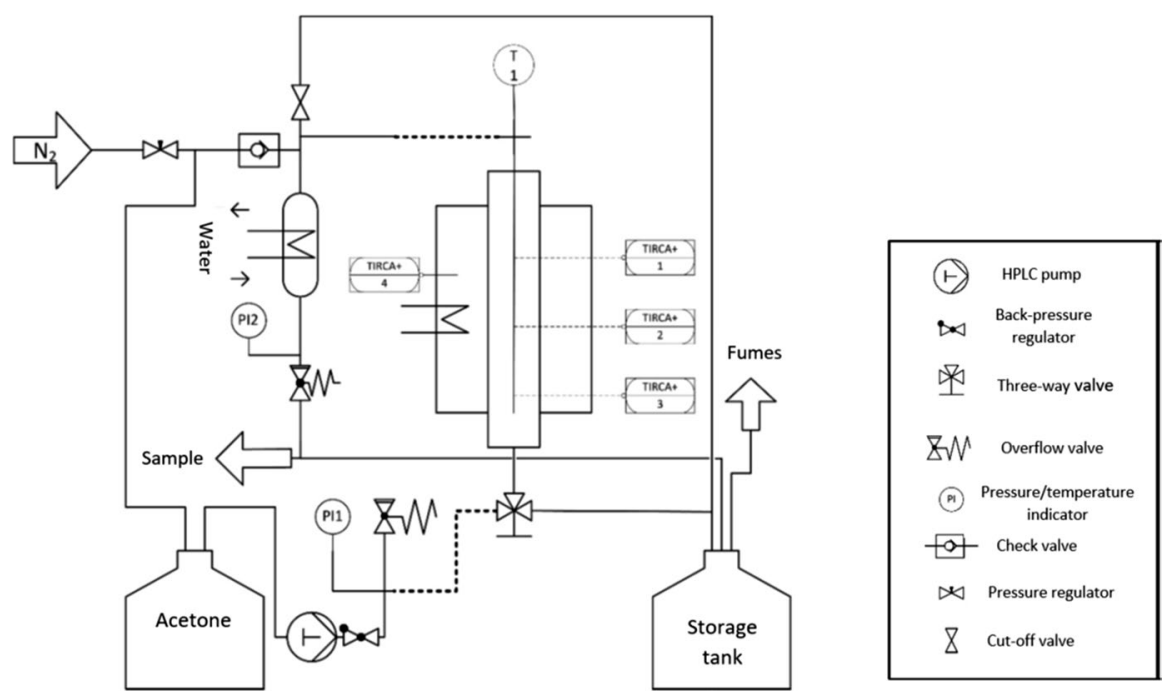

Fig. 11 Process flow diagram of the fixed bed reactor for the aldol reaction of acetone

These results can be explained by three different deactivation mechanisms, discussed in the next chapters: Hofmann rearrangement, organic fouling and deactivation by acetic acid and dissolved carbon dioxide.

\section{Hofmann rearrangement}

The Hofmann rearrangement deactivates the ion exchange resin by elimination of amines [39]. This reduces the quantity of quaternary ammonium groups which means a decrease in the number of strong basic active sites. The strong anion exchange capacity can be determined by titration using DIN 54,402 [40]. Without water addition the strong anion exchange capacity is reduced by $17 \%$, with water 
addition the reduction is only $6 \%$ (Table 1 ). With water addition a bigger hydrate sphere around the ions of the ion exchange resin is present which protects the quaternary ammonium group against the Hofmann rearrangement [41].

\section{Organic fouling}

Beside the lower deactivation by Hofmann rearrangement, less organic fouling by higher molecular by-products based on MO is observed. This could be monitored by change of color. In the wet state the Amberlyst A26OH is pink. In acetone the color changes to beige, and during the experiments without water addition the color changes to dark brown. The dry weight of the catalyst increases. With water addition the color changes to light brown, and the dry weight of the catalyst increases less (Table 1). Color change and gaining weight are caused by the incorporation of reaction products. Due to this incorporation, pores of the catalyst are blocked and cannot be accessed by reactant anymore.

\section{Neutralisation of active sites by acetic acid}

A third effect that deactivates the catalyst is the content of acetic acid and dissolved carbon dioxide in acetone. For ACS reagent grade acetone this titrable acid content is 0.0003 mequiv $\mathrm{g}^{-1}$ [42]. The deactivation mechanism is not affected by water addition. Acetone has a density of $0.79 \mathrm{~g} \mathrm{~mL}^{-1}$ at $20^{\circ} \mathrm{C}$. After $48 \mathrm{~h}$ with a flow rate of $2 \mathrm{~mL} \mathrm{~min}^{-1} 4550.4 \mathrm{~g}$ acetone have passed through the reactor. This accords to 1.365 mequiv acid. $6 \mathrm{~g}$ wet Amberlyst A26OH contain 7.1 mequiv active sites, i.e. up to $19 \%$ of the active sites can be neutralized by acid.

This deactivation is reversible by regeneration of the ion exchange resin with sodium hydroxide. The deactivation caused by Hofmann elimination and organic fouling is irreversible. The catalyst deactivation by acetic acid and dissolved carbon dioxide in the acetone is another reason for the decreasing conversion at higher flow rates.

Table 1 Strong anion exchange capacity and dry weight of $6.00 \mathrm{~g}$ Amberlyst A26OH

\begin{tabular}{llll}
\hline & Unused catalyst & $\begin{array}{l}\text { After } 48 \mathrm{~h} \text { at } 20{ }^{\circ} \mathrm{C} \text { reaction } \\
\text { with water addition }\end{array}$ & $\begin{array}{l}\text { After } 48 \mathrm{~h} \text { at } 20{ }^{\circ} \mathrm{C} \\
\text { reaction without water } \\
\text { addition }\end{array}$ \\
\hline $\begin{array}{l}\text { Strong anion } \\
\text { exchange capacity } \\
\text { Dry weight }\end{array}$ & 7.1 mequiv & 6.7 mequiv & 5.9 mequiv \\
\hline
\end{tabular}




\section{Experimental section}

\section{Catalyst and chemicals}

The catalyst applied in our experiments was Amberlyst A $26 \mathrm{OH}$ (for characteristics see [34]). This commercial material is based on a styrene polymer cross linked with divinyl benzene. It is functionalized by quaternary ammonium groups. This anionic ion exchange resin, type 1 was kindly provided by DuPont. The acetone used was in BioRenewable grade purchased from Merck.

\section{Batch reactions}

For the batch reactions the following conditions were applied:

Catalyst: 3 g Amberlyst A $26 \mathrm{OH}$ which contains $0.7 \mathrm{~g}$ water (used as delivered). Reagent: $50 \mathrm{~mL}$ acetone and $1.8 \mathrm{~mL}$ water.

Temperature range: $0-45^{\circ} \mathrm{C}$,

Reaction time: 2-96 h.

The catalyst was placed in a $100 \mathrm{~mL}$ two-necked bottom flask together with acetone and water. The flask was equipped with a magnetic stirring bar, septum, and reflux condenser. The desired temperature was adjusted in an oil bath. Temperatures between $0{ }^{\circ} \mathrm{C}$ and $10{ }^{\circ} \mathrm{C}$ could be achieved using a cryostat. The first sample was taken $1 \mathrm{~h}$ after starting the reaction. For taking samples a syringe with filter (PTFE; $1 \mu \mathrm{m}$ ) was used to ensure that no catalyst particles remain in the sample. Further samples were taken after 2, 3, 4, 20, 75, and $96 \mathrm{~h}$. Conversion and selectivity were determined by GC analysis.

\section{Reactions in a continuous flow fixed bed reactor}

The continuous reactions were conducted in a fixed bed reactor applying an upflow mode to prevent an accumulation of gases in the fixed bed. The catalyst was washed with $50 \mathrm{~mL}$ acetone to remove most of the water. Temperatures were controlled by a thermostat.

Catalyst: $6 \mathrm{~g}$ Amberlyst A $26 \mathrm{OH}$ (wet, as delivered).

Reagent: $5000 \mathrm{~mL}$ acetone and $250 \mathrm{~mL}$ water.

Temperature steps: $-24-45^{\circ} \mathrm{C}$.

Flow rate: $1 \mathrm{~mL} \min ^{-1} ; 2 \mathrm{~mL} \min ^{-1} ; 4 \mathrm{~mL} \mathrm{~min}^{-1} ; 10 \mathrm{~mL} \min ^{-1}$.

Reaction time: between 2 and $120 \mathrm{~h}$.

Reactor: Length: $15 \mathrm{~cm}$, Diameter: $1.35 \mathrm{~cm}$.

Conversion and selectivity as responding parameters were determined by GC analysis.

\section{GC analysis}

GC analysis was carried out on a 25 m FS-FFAP column using a HP6890 Plus chromatograph. Dodecane was used as internal standard. 


\section{Conclusion}

The combination of using a strong basic ion exchange resin at low temperatures with water addition has three major advantages for the aldol reaction of acetone:

(1) A higher conversion at lower temperatures (max. $20.2 \%$ at $0{ }^{\circ} \mathrm{C}$ )

(2) A high selectivity of 98-99\%

(3) A longer catalyst lifetime, due to suppression of Hofmann rearrangment and organic fouling

In the temperature range from 0 to $45^{\circ} \mathrm{C}$, the equilibrium conversion of acetone to DAA is a linar function of temperature. The possible conversion of acetone to DAA is a good criterion to estimate the conversion in a fixed bed reactor. At $0{ }^{\circ} \mathrm{C}$ and a weight hourly space velocity (WHSV) of $7.9 \mathrm{~h}^{-1}$ an equilibrium conversion of $20.2 \%$ can be reached.

It was found that the selectivity for DAA in a fixed bed reactor is higher than in a batch reactor. The short contact time inhibits as expected most of the consecutive reactions. Furthermore, the addition of water has a positive effect on the selectivity of DAA. By-products of the aldol reaction of acetone to DAA are MO and TAA. In the presented process it is possible to determine the by-products as a function of temperature. At $0{ }^{\circ} \mathrm{C}$ and below TAA is the only by-product. With increasing temperature, the amount of TAA decreases, and MO became the main by-product.

The addition of water has also a positive effect on the service time of the used ion exchange resin as in the case of low temperatures. Thereby, two of the three deactivation mechanisms are reduced. Less organic fouling caused by higher molecular by-products and less deactivation by Hofmann elimination were observed. Without water addition both deactivation effects are about three times stronger (17\% loss in strong ion exchange capacity vs. $6 \%$ with water addition).

Acknowledgements This work was financially supported by DSM Nutritional Products, Kaiseraugst/ Basel, Switzerland.

Funding Open Access funding enabled and organized by Projekt DEAL.

Open Access This article is licensed under a Creative Commons Attribution 4.0 International License, which permits use, sharing, adaptation, distribution and reproduction in any medium or format, as long as you give appropriate credit to the original author(s) and the source, provide a link to the Creative Commons licence, and indicate if changes were made. The images or other third party material in this article are included in the article's Creative Commons licence, unless indicated otherwise in a credit line to the material. If material is not included in the article's Creative Commons licence and your intended use is not permitted by statutory regulation or exceeds the permitted use, you will need to obtain permission directly from the copyright holder. To view a copy of this licence, visit http://creativecommons.org/licen ses/by/4.0/. 


\section{References}

1. Berezina OV, Zakharova NV, Yarotsky CV, Zverlov VV (2012) Microbial producers of butanol. Appl Biochem Microbiol 48:625-638. https://doi.org/10.1134/S0003683812070022

2. Dürre P (2007) Biobutanol: an attractive biofuel. Biotechnol J 2:1525-1534. https://doi.org/10. 1002/biot.200700168

3. Xue C, Zhao X-Q, Liu C-G, Chen L-J, Bai F-W (2013) Prospective and development of butanol as an advanced biofuel. Biotechnol Adv 31:1575-1584. https://doi.org/10.1016/j.biotechadv.2013.08. 004

4. E4tech, RE-CORD, WUR (2015) From the sugar platform to biofuels and biochemicals: final report for the european commission directorate- general for energy. https://ec.europa.eu/energy/sites/ener/ files/documents/ECSugarPlatformfinalreport.pdf. Accessed 14 Sep 2021

5. PubChem, Center for Biotechnology Information (2020) 1-Butanol. https://pubchem.ncbi.nlm.nih. gov/compound/263. Accessed 20 Sep 2021

6. Zverlov VV, Berezina O, Velikodvorskaya GA, Schwarz WH (2006) Bacterial acetone and butanol production by industrial fermentation in the Soviet Union: use of hydrolyzed agricultural waste for biorefinery. Appl Microbiol Biotechnol 71:587-597. https://doi.org/10.1007/s00253-006-0445-z

7. Weber M, Weber M, Weber V (2000) Phenol. In: Ullmann's Encyclopedia of Industrial Chemistry. Wiley, pp 1-20

8. Heintz W (1873). Ann 114-120

9. Conant JB, Tuttle N (1921) Diacetone Alcohol. Org Synth. 1:45 https://doi.org/10.15227/orgsyn. 001.0045

10. Conant JB, Tuttle N (1921) Mesityl Oxide. Org Synth 1:53. https://doi.org/10.15227/orgsyn.001. 0053

11. Abel H, Raisin H (1987) Dyeing aid and its use in dyeing or optically brightening synthetic nitrogen-containing fibrous materials. EP0235080 (A1)

12. Tietze L, Eicher T (1991) Reaktionen und Synthesen im organisch-chemischen Praktikum und Forschungslaboratorium, 2nd edn. Georg Thieme Verlag, New York

13. Sell C (2006) The chemistry of fragrances: from perfumer to consumer, $2^{\text {nd }}$ ed. RSC popular science. RSC Publishing, Cambridge, UK

14. Hawkins C, Yeomans B (1976) Process for the production of diacetone alcohol. GB1527033 (A)

15. Guthrie JP (1978) Equilibrium constants for a series of simple aldol condensations, and linear free energy relations with other carbonyl addition reactions. Can J Chem 56:962-973. https://doi.org/10. $1139 / \mathrm{v} 78-162$

16. Craven EC (1963) Alkaline condensation of acetone. J Appl Chem 71

17. Yokoyama K, Iwade S, Isogai S (2004) Process for producing diacetone alcohol. WO2004101485 (A1)

18. Osei TEY, Hassan N, Elwaer N et al (2015) Synthesis of diacetone alcohol and mesityl oxide. WO2016012974 (A1)

19. Bonrath W, Fleischhauer H, Hoelderich WF et al (2008) Aldol condensation reaction and catalyst therefore. WO2008145350 (A1)

20. Thotla S, Mahajani S (2009) Reactive distillation with side draw. Chem Eng Process 48:927-937. https://doi.org/10.1016/j.cep.2008.12.007

21. Tzompantzi F, Valente JS, Cantu MS, Gomez R (2007). Chemical Industries 55

22. Winter F, van Dillen AJ, de Jong KP (2005) Supported hydrotalcites as highly active solid base catalysts. Chem Commun. https://doi.org/10.1039/b506173c

23. Roelofs JCAA, Lensveld DJ, van Dillen AJ, de Jong KP (2001) On the structure of activated hydrotalcites as solid base catalysts for liquid-phase aldol condensation. J Catal 203:184-191. https://doi. org/10.1006/jcat.2001.3295

24. Thothla S, Agarwal V, Mahajani SM (2007) Aldol condensation of acetone with reactive distillation using water as a selectivity enhancer. Ind Eng Chem Res. https://doi.org/10.1021/ie061658+

25. Tanabe K, Hoelderich WF (1999) Industrial application of solid acid-base catalysts. Appl Catal A 181:399-434. https://doi.org/10.1016/S0926-860X(98)00397-4

26. Tanabe K (1989) New solid acids and bases: their catalytic properties. Studies in surface science and catalysis, vol 51. Elsevier, Amsterdam

27. Di Girolamo M, Marchionna M (2001) Acidic and basic ion exchange resins for industrial applications. J Mol Catal A: Chem 177:33-40. https://doi.org/10.1016/S1381-1169(01)00307-7 
28. Bonrath W, Pressel Y, Schütz J, Ferfecki E, Topp K-D (2016) Aldol condensations catalyzed by basic anion-exchange resins. ChemCatChem 8:3584-3591. https://doi.org/10.1002/cctc.201600867

29. Nozawa R, Fujita K, Chiyou S et al (1981) Preparation of diacetone alcohol. JPS5859936 (A)

30. Harada H, Hamada K, Masuko F (1984) Continuous production of diacetone alcohol. JPS615040 (A)

31. Podrebarac GG, Ng FTT, Rempel GL (1998) The production of diacetone alcohol with catalytic distillation. Chem Eng Sci 53:1067-1075. https://doi.org/10.1016/S0009-2509(97)00427-2

32. Podrebarac GG, Ng FTT, Rempel GL (1998) The production of diacetone alcohol with catalytic distillation. Chem Eng Sci 53:1077-1088. https://doi.org/10.1016/S0009-2509(97)00428-4

33. Kim YK, Hatfield JD (1985) Kinetics and equilibrium data of the dehydration-hydration reaction between diacetone alcohol and mesityl oxide in phosphoric acid. J Chem Eng Data 30:149-153. https://doi.org/10.1021/je00040a005

34. DuPont (2020) ProductDataSheet AMBERLYST ${ }^{\mathrm{TM}}$ A26 OH PolymericCatalyst: FormNo.45D00939-en, Rev.0

35. Schwetlick K (2001) Organikum: Organisch-chemisches Grundpraktikum, 21st edn. Wiley-VCH, Weinheim

36. Rapson WS, Robinson R (1935) 307. Experiments on the synthesis of substances related to the sterols. Part II. A new general method for the synthesis of substituted cyclohexenones. J Chem Soc. https://doi.org/10.1039/JR9350001285

37. Cabani S, Ceccanti N (1966) Equilibria and kinetics of the hydration and cyclisation of semiphorone in acidic media. J Chem Soc B. https://doi.org/10.1039/j29660000077

38. Siva Kumar V, Nagaraja BM, Shashikala V, Seetharamulu P, Padmasri AH, David Raju B, Rama Rao KS (2004) Role of acidic and basic sites of Al2O3 in predicting the reaction pathway of isophorone transformation. J Mol Catal A: Chem 223:283-288. https://doi.org/10.1016/j.molcata.2003. 08.034

39. Banthorpe DV, Hughes ED, Ingold C (1960) 799. Mechanism of elimination reactions. Part XX. The inessentiality of steric strain in bimolecular olefin elimination. J Chem Soc. https://doi.org/10. $1039 / j \mathrm{r} 9600004054$

40. DIN 54402:2009-04 Testing of ion exchangers - Determination of the total capacity of anion exchangers

41. Okada T, Harada M, Ohki T (2009) Hydration of ions in confined spaces and ion recognition selectivity. Anal Sci 25:167-175. https://doi.org/10.2116/analsci.25.167

42. American Chemical Society (2000) Reagent chemicals: american chemical society specifications, official from January 1, 2000, 9th edn. American Chemical Society, New York, NY

Publisher's Note Springer Nature remains neutral with regard to jurisdictional claims in published maps and institutional affiliations. 